\title{
Radiation Exposures in Clinical Diagnostic Studies
}

\author{
Gul M. Chughtai, Ph.D.* \\ Eugene C. Maso, M.D.
}

\section{DOI: http://dx.doi.org/10.5915/17-1-12721}

The basic objective of this paper is to outline radiation doses to various critical organs of an average adult person during $x$-ray procedures and clinical studies in Nuclear Medicine. A comparative study is conducted to confirm clinical exposure using thermoluminescent dosimeters. Absorbed doses to critical organs are also computed. Radiation doses vary for different types of examinations and techniques. Repeats of x-ray and unnecessary clinical examinations can cause harmful effects. Biological effects of radiation for pregnant women and her fetus in early pregnancy have been discussed. To minimize radiation exposure and improve quality of image various factors have been reviewed. Routine calibration of $x$-ray units and implementation of effective quality assurance program can reduce the radiation exposure and achieve the optimal clinical objective.

\section{Introduction}

Radiation has an important role in medicine. Ionizing radiation is used in different imaging modalities such as digital radiology, digital subtraction angiography, computed tomography, dentistry, fluoroscopy, mammography, diagnostic x-ray and Nuclear Medicine. In addition to these, ultrasonography and magnetic resonance imaging are also of great clinical importance to diagnose any abnormality in human body. Medical radiation exposures to patients during diagnostic studies depend on various factors. In Nuclear Medicine procedures the absorbed dose depends on the amount of radioisotope being injected. In diagnostic $x$-ray procedures the exposure depends on Kilovoltage, milliampers, target to skin distance, field size, required projections, sex, age and thickness of the patients'. The dose to critical organs will be higher in the primary useful radiation beam. Radiation measurement in these procedures can assist in establishing safety guidelines for the public and the radiation workers. Presently 5 Rem* for occupationally exposed persons and $0.5 \mathrm{Rem}$ for the general public have been considered as safe limits $^{2}$. Radiation poses more potential hazard to pregnant women and her fetus during early pregnancy. High radiation dose to mother can result in embryo death or leukemia can be induced during childhood ${ }^{3}$. Federal agencies, state and other regulatory agencies such as JCAH (Joint Commission on Accreditation of Hospitals) have strongly recommended establishing good quality assurances procedures to minimize unnecessary radiation exposures.

Rem: Radiation absorbed dose unit ( $\operatorname{Rad} \times$ RBE value). Relative Biological Effect (RBE) is a factor of different types of radiation.

\section{Method and Equipment}

Experimental data was obtained to measure skin exposure using thermoluminescent dosimeters. Teflonmixed lithium fluoride chips (TLD-100, 1/8" $\mathrm{x} 0.035^{\prime \prime}$ ) were placed directly on the skin of the patients during diagnostic examination. The exposed TLD's were read by a Harsha Model 2000-B automatic integrating picometer. TLD's were calibrated with low energy $x$ rays and annealed before using for dosimetry. TLD's measured values for different types of examinations were compared with computer calculated skin exposure values from Dupont radiographic techniques guide. The results are shown in table 1 and graphically in figures 1 and 2. These results vary from 3 to $10 \%$. This variation is due to calibration and annealing techniques of TLD's. Estimated absorbed doses for various critical organs are computed from the skin exposure data ${ }^{5}$ and reported in table 2 . Absorbed doses to critical organs in Nuclear Medicine are reported in table 3. These doses are computed from the technical data provided by the manufacturers of radiopharmaceuticals and reference books ${ }^{6}, ?$.

\section{Discussion}

The reported radiation doses in clinical studies are within safe limits. The repeats of $\mathrm{x}$-ray procedures and misadministration of radiopharmaceutical will increase the risk of radiation damage. In Nuclear Medicine, care must be taken to avoid $\mathrm{I}^{131}$ thyroid scan or chest scan to a pregnant woman during her early pregnancy. As the deposition of $\mathrm{I}^{131}$ radioiodine in the fetus thyroid can give high radiation dose and can cause a high risk of leukemia to newborn children during childhood. There

\footnotetext{
From the Department of Radiology

* Malcolm Grow USAF Medical Center, Andrews Air

Force Base, Washington, D.C.

Presented at the 17th Annual Convention of the Islamic Medical Association, St. Louis, Missouri August 10-12, 1984

*Address all correspondence to Dr. Gul M. Chughtai Dept. of Radiology, Malcolm Grow USAF Medical Center Andrews Air Force Base, Washington, DC 20331

* Contents presented in this paper are of the authors and not of the USAF
} 


\begin{tabular}{|c|c|c|c|}
\hline $\begin{array}{l}\text { Type } \\
\text { if } \\
\text { Eximinutien }\end{array}$ & 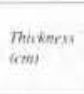 & $\begin{array}{l}n D \text { i } \\
\text { Measurrmerni } \\
\text { inRi }\end{array}$ & 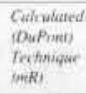 \\
\hline Chrst PA & 20.23 & 36 & 30 \\
\hline tostrral & $32-35$ & 47 & 45 \\
\hline Atmdimen & 18.10 & 315 & 300 \\
\hline Stailf AP & $10-29 \mid$ & 355 & 300 \\
\hline twteral & 14.15 & 125 & 120 \\
\hline Ribx, Bariam Swation & $20-28$ & 225 & 400 \\
\hline Shessider & 12:14 & 80 & so \\
\hline Crnixul Syme AP & 80 & 45 & 40 \\
\hline Luterul & $\Leftrightarrow 7$ & 110 & 100 \\
\hline Lamber Sprine & $18-14$ & 420 & 400 \\
\hline Hip AP & 18.70. & $2 n 0$ & 250 \\
\hline Prive & 20.21 & 45 & $9 / 5$ \\
\hline fermut & $12 \cdot 14$ & 172 & (x) \\
\hline
\end{tabular}

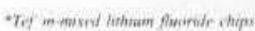

Tahle 2 ESTIMATED RADIATION DOSES TO CRITICAL ORGANS IN X.RAY EXAMINATIONS

Type of Study Skin Dose Testes Ovaries Thyoud Active Bone Marrow Embryorm Rad

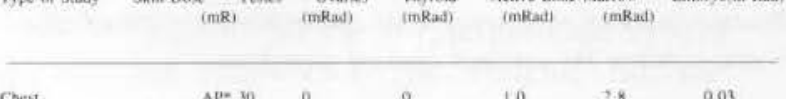

\begin{tabular}{|c|c|c|c|c|c|c|}
\hline Chest & $\begin{array}{l}A^{P}=30 \\
t_{a t}=45\end{array}$ & $\begin{array}{l}0 \\
0\end{array}$ & ? & $\begin{array}{r}1.0 \\
4.5\end{array}$ & $\begin{array}{l}2.8 \\
1.4\end{array}$ & $\begin{array}{l}0.03 \\
0.02\end{array}$ \\
\hline Skuti & $\begin{array}{l}\text { AP: } 300 \\
\text { Lat } 120\end{array}$ & 0 & 0 & $\begin{array}{l}152 \\
28\end{array}$ & $\begin{array}{l}5 \\
6\end{array}$ & $\begin{array}{l}0 \\
0\end{array}$ \\
\hline
\end{tabular}

\begin{tabular}{lllllll}
\hline Abdominal & 300 & 10.4 & 132 & 0.01 & 21.5 & 172 \\
\hline Lumbar Spine & 400 & 18 & 94 & 0.16 & 16 & 125
\end{tabular}

\begin{tabular}{|c|c|c|c|c|c|c|}
\hline Ribs, Aarium Swallow & 400 & o & 0.08 & 36 & 48 & 0.07 \\
\hline Pelvis & 515 & 39 & 131 & 0 & 16 & 141 \\
\hline Cervical Spine & $\begin{array}{l}\text { AP: } 40 \\
\text { Lat: } 100\end{array}$ & 0 & 0 & $\begin{array}{l}133 \\
17\end{array}$ & $\begin{array}{l}1.8 \\
8.3\end{array}$ & 0 \\
\hline Hip & AP 250 & 185 & 29 & 0 & 40 & 60 \\
\hline Showalder & 80 & 0 & 0 & 0 & 1.7 & 0 \\
\hline Femur & 160 & 48 & 1.0 & 9 & 1.2 & 12 \\
\hline
\end{tabular}

AP- antero posienot

is no significant damage to the fetus from 1 to 5 rads of radiation dose. It has been reported that the increased risk of leukemia from 2 rads is 1 in 2000 . The abortion is considered up to $10 \mathrm{rad}$. However, this decision is based on the expectant mother's ethnic and religious background ${ }^{4}$ and advice of the physician.

In diagnostic $\mathrm{x}$-ray, the radiaition can be reduced by implementing effective quality control procedures, introducing faster film system, improved collimation and image intensifying devices. Radiation doses can be further reduced with additional filtration of Yttrium. It has been reported that ( $3 \mathrm{~mm} \mathrm{Al} \pm 0.1 \mathrm{~mm}$ Yttrium) filters can reduce radiation exposure from $50 \%$ to $70 \%$ without affecting the quality of image ${ }^{10}$. With the implementation of good quality control procedures for equipment and diagnostic procedures, strict adherence to the existing regulations will reduce the risk of radiation hazard and will increase the patient care.

\section{References}

1. Heller, MB: "Reduction of Radiation Dose in

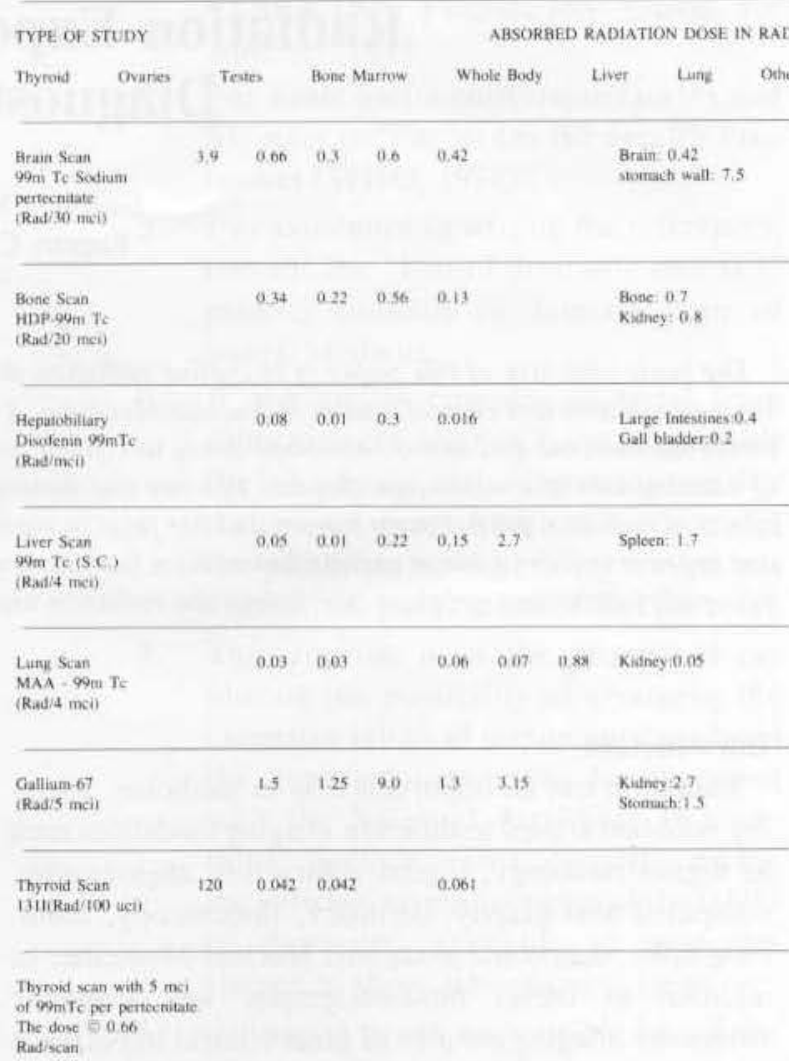

Diagnostic X-ray Procedures; Proceedings of a Symposium held in Houston, Texas, 1971.

2. NCRP (report \#39) Basic Radiation Protection Criteria (1971).

3. Fabrikant, JI: Biological Effects of Small Doses of Radiation, DHEW Publication No. (FDA) 73-8209, Sept, (1972)

4. Medical Radiation Exposure of Pregnant and Potentially Pregnant Women, National Council in Radiation Protection and Measurements (NCRP report \#54) 1979

5. Rosenstein, M: (1976) Handbook of Selected Organ Doses for Projections Common in Diagnostic Radiology, DHEW publication (FDA) 76-3080.

6. Dillman, LT: Radionuclide Decay Schemes and Nuclear Parameters for Use in Radiation Dose Estimation. MIRD pamphlet No. 10 (1975)

7. A Schema for Absorbed Dose Calculation for Biologically Distributed Radionuclide, supplement No. 1, MIRD pamphlet No. 1 J. Nucl. Med. p.7. 1968.

8. Russell, LB: (1954), "The Effects of Radiation on Mammelian Prenatal Development", p.861, Radiation Biology, vol. 1, Hollaonder A. Ed (McGraw Hill: NY)

9. Oppenheimer, BE, et al. (1975). "'The Effects of Diagnostic X-ray Exposure on a Human Fetus: An Examination of the Evidence", Radiology 114 , 529.

10. Yen Wang et al, "Clinical Applications of Yttrium Filters for Exposure Reduction, Radiographics, vol. 4, no. 3. (1984)

11. Lindell, B, et al, (1961) Ionizing Radiation and Health, Public Health Papers, no. 6 (WHO, .Geneva) 